\title{
Current status and future perspectives on treatment of liver metastasis in colorectal cancer (Review)
}

\author{
MAHDI HUSSAIN AL BANDAR and NAM KYU KIM \\ Department of Surgery, Yonsei University, College of Medicine, Seoul 120-752, Republic of Korea
}

Received December 25, 2016; Accepted March 13, 2017

DOI: $10.3892 / o r .2017 .5531$

\begin{abstract}
Liver metastasis is the most common site of colorectal cancer (CRC) metastasis. Approximately half of all colorectal cancer patients will develop liver metastases. Although radical surgery is the standard treatment modality, only $10-20 \%$ of patients are deemed eligible for resection. Despite advances in survival with chemotherapy, surgical resection is still considered the only curative option for patients with liver metastases. Much effort has been expended to address patients with metastatic liver disease. The majority of evidence stated a significant survival benefit with surgical resection to reach an overall 5-year survival rate of 35-55\% after hepatic resection. However, still majority of patients will experience disease recurrence even after a successful resection. In this review, we describe current status and controversies related to treatment options for CRC liver metastases and its potential for enhancing oncologic outcomes and improving quality of life.
\end{abstract}

\section{Contents}

1. Introduction

2. CRC liver metastasis treatment challenges: What are the limitations of liver resection?

3. Synchronous unresectable CRCLM (uCRCLM)

Correspondence to: Dr Nam Kyu Kim, Department of Surgery, Division of Colorectal Surgery, Colorectal Cancer Special Clinic, Yonsei University, College of Medicine, 50 Yonsei-roSeodaemun-gu, Seoul 120-752, Republic of Korea

E-mail: namkyuk@yuhs.ac

Abbreviations: CRT, chemoradiotherapy; CRC, colorectal cancer; CRCLM, colorectal liver metastasis; rCRCLM, resectable CRCLM; FLR, future liver remnant; TSH, two stage hepatectomy; HR, hepatic resection; RT, radiotherapy; ALPPS, associating liver partition and portal vein ligation for staged hepatectomy; SIRT, selective internal radiotherapy

Key words: metastatic, colorectal cancer, management debates, liver metastasis
4. Ablative modalities for liver metastasis

5. Portal vein embolization (PVE)

6. Emerging techniques in addressing uCRCLM

7. Selective internal radiotherapy (SIRT)

8. Conclusion

\section{Introduction}

Worldwide, colorectal cancer (CRC) has become the thirdmost common type of malignancy and fourth-most frequent cause of cancer-related mortality. The CRC metastasis rate has increased steadily to $20-25 \%$ (1-4), and $70-80 \%$ of these cases occur in the liver (5). Almost half of all patients who undergo resection for primary CRC will eventually develop metachronous liver metastases (6), the leading cause of death in this population with a median overall survival (OS) duration of 6-12 months if left untreated (7). Surgical resection is the mainstay of treatment for colorectal liver metastasis (CRCLM); however, liver metastases are deemed resectable in only $10-20 \%$ of cases (8) with disappointing results and high recurrence rate. One multi-center study of 1669 patients found that more than half developed recurrences, with median disease-free survival duration of 16.3 months (9).

Therefore, various alternative options for CRCLM management have been extensively studied. However, definition debates add serious strain in designing management plan. Particularly in resection for cure was very low in synchronous compared to metachronous, however, new chemotherapy agent has a role to improve resection rate up to 30-40\% (5). Definition of synchronous metastases is still debated, although it has been highly suspected in those detected up to 3 (10), $4(11)$, or 6 months $(12,13)$ after the primary diagnosis.

Noteworthy, multidisciplinary team decision-making and evolving chemotherapy agents and patient care are contributed to improve 5-year OS rates from $<8 \%$ to $25-40 \%(14,15)$. Neoadjuvant treatment, which is used for local tumor amelioration, has a high response rate $(>50 \%)$ and can increase the rate of resectability from 10 to $30 \%(16,17)$, although the recurrence rate still remains high, with OS not exceeding 3 years (18). Therefore, alternative treatment strategies are essential. We reviewed current data and analyzed existing treatment modalities. We hope this review will generate prospective insights into ongoing controversies regarding the management of liver metastases of CRC. 


\section{CRC liver metastasis treatment challenges: What are the limitations of liver resection?}

Generally, liver metastasis cas manifest in both synchronous or metachronous forms. These presentations raise questions regarding the ability to resect the primary tumor, liver metastasis, or both and when to consider different forms of radiotherapy with or without chemotherapy. In the following section, management of synchronous CRCLM will be elaborated in details.

\section{Synchronous resectable CRCLM}

Extent of liver resection. Liver resection is the only potentially curative treatment for CRCLM (19). The major concern involves the achievement of $\mathrm{R} 0$ resection without consequent complications, particularly the avoidance of an insufficient future liver remnant (FLR) during major hepatectomy. Decision to estimate FLR is left for surgeon decision that depends mainly in the status of the liver preoperatively. For instance; resection up to $75 \%$ is adequate in normal liver, however patients with chronic liver disease but without cirrhosis usually require an FLR of at least $30 \%$ while patients with cirrhosis but without portal hypertension require an FLR of at least $40 \%(20,21)$.

Dam et al (22) compared limited (criteria: <3 unilateral, non-centrally located liver metastases, no extrahepatic metastases) and extended hepatectomy in 298 patients with CRCLM. Patients who underwent limited resection had a lower complication rate $(19.5 \%$ vs. $33.1 \%, \mathrm{P}<0.01)$, longer OS duration (68.8 months vs. 41.4 months, $\mathrm{P} \leq 0.001$ ), and longer median disease-free survival (DFS; 22.0 months vs. 10.2 months), compared with the extended group. Based on these criteria, only 15-20\% of CRCLMs will be suitable for resection. Recent advances in chemotherapy have increased the indications of liver resection. Accordingly, all of the previous criteria have been largely abandoned $(23,24)$. Patients with stable health, $\geq 4$ lesions, bilateral metastases, no extrahepatic metastases, and adequate FLR are considered resectable and may achieve 5-year DFS and OS rates of 21.5 and $50.9 \%$, respectively $(25,26)$.

In addition, addressing management of extra-hepatic metastasis (EHM) along with CRCLM is challenging and may end with dismal outcome; however, surgical intervention can improve OS in resectable cases. What to do and when to consider resection? We could estimate the current inquiry from the results of an international multi-institutional analysis (27) involving 1629 patients who underwent resection of CRCLM found that most patients had solitary EHM, and the 5-year survival rates were 26 and $58 \%$ for those with and without EHM, respectively $(\mathrm{P}<0.01)$. In addition, EHM characteristics such as R1 margin positivity, multiple sites, and location were associated with worse survival. Accordingly, EHM resection is possible in selected patients without presence of extensive disease.

The selection criteria for liver resection are essential in order to avoid an inadequate FLR, a major cause of surgery-related death. Normally, patients can survive with only $20 \%$ of a healthy normal liver. However, for patients whose livers are affected by chemotherapy or who expect to receive postoperative chemotherapy, $30-40 \%$ of the liver should be preserved $(28,29)$. Liver resection is planned if a complete R0 resection is feasible, at least 2 liver segments with independent inflow and outflow are spared, and appropriate biliary drainage is maintained.

Management options in resectable CRCLM, surgery or chemotherapy first? The choice to administer initial surgical or chemotherapeutic treatment remains a subject of debate. However, upfront liver metastasis resection is the primary treatment modality for resectable CRCLM (rCRCLM) (30-32), however, most of such cases presented with a higher recurrence rate (33). Therefore, the National Comprehensive Cancer Network (NCCN) recommends 6 months of perioperative systemic chemotherapy. However, standard policy and treatment strategy are poorly defined (34). Currently, alternative treatment has been tried and introduced radiofrequency ablation (RFA) in resectable CRCLM, which has failed to generate good results. A recent meta-analysis (35) agreed with this fact, they investigated the role of RFA vs. resection for rCRCLM and found that the former was associated with poorer OS (hazard ratio (HR): $1.85,95 \%$ confidence interval (CI): 1.48-2.32, $\mathrm{P}<0.00001$ ) and DFS (HR: 1.68, 95\% CI: 1.14-2.48, $\mathrm{P}=0.009$ ).

Thereafter, neoadjuvant chemotherapy has been proposed to assess tumor biology, at which chemotherapy could be prolonged and surgery would be delayed in poor responders until good response was shown $(36,37)$. Adam et al (38), enrolled 131 patients with rCRCLM found worse 5-year survival in poor responders compared to stable or responsive disease ( $8 \%$ vs. $30 \%, 37 \%$; $\mathrm{P}=0.0001$ ), respectively. Moreover, Ruenberger et al (39) conducted a prospective trial to assess the efficacy of 6 cycles of neoadjuvant XELOX or FOLFOX4 in 50 patients with rCRCLM demonstrating recurrence-free survival rates correlated with tumor responses $(24.7,8.2$, and 3.0 months) in responsive, stable, and progressive disease, respectively. Based on these results, perioperative chemotherapy upfront could be an essential partto assess tumor response, which is supported by EORTC 40983 studies (16). However, these studies reported chemotherapy-associated liver damage and a significantly higher rate of postoperative complications with chemotherapy than with surgery alone (25\% vs. $16 \%)$. Therefore, chemotherapy may cause liver injury and poor short-term prognosis consequently (40). Other studies including those of EORTC 40983 found an association between high morbidity rate and the number of chemotherapy cycles $(17,41,42)$, suggested that a period of 3 months preoperative FOLFOX-4 chemotherapy should not br exceed in order to avoid chemotherapy-related liver toxicity (39).

A very recent systematic review from 2016 (43), summarized four well-organized trials addressing the role of chemotherapy to rCRCLM. Two trials demonstrated significant improvements in DFS with combined chemotherapy and surgery, compared to surgery alone. FOLFOX, along with liver resection, yielded improvements in DFS, compared to surgery alone. In addition, a new EPOC randomized controlled trial (44), posted encouraging results regarding the addition of the molecular target agent cetuximab to chemotherapy for operable CRCLM. Progression-free survival (PFS) was significantly shorter with cetuximab than with chemotherapy alone (14.1 vs. 20.5 months, respectively). OS, however, remains under investigation. Discrepancies in the reported survival benefits with neoadjuvant chemotherapy remain under debate, as illustrated in Table I. 
Table I. Chemotherapy trials in resectable CRCLM.

\begin{tabular}{|c|c|c|c|c|c|c|}
\hline Study & Year (study) & No. & Patient & $\operatorname{Aim}(\mathrm{N})$ & Control (N) & Outcome (months) \\
\hline $\begin{array}{l}\text { Primrose et al (44) } \\
\text { EPOC }\end{array}$ & 2014 (RCT) & 236 & $\begin{array}{l}\text { rCRCLM } \\
\text { wt KRAS }\end{array}$ & $\begin{array}{l}\text { FOLFOX+Cetuximab } \\
(119)\end{array}$ & $\begin{array}{l}\text { FOLFOX } \\
(117)\end{array}$ & $\begin{array}{l}\text { PFS (14.1 vs. } 20.5) \\
\text { Higher complication }\end{array}$ \\
\hline $\begin{array}{l}\text { Nordlinger } \text { et al } \\
\text { EORTC } 40983 \text { (122) }\end{array}$ & $\begin{array}{l}2013 \\
(\mathrm{RCT}+78 \mathrm{MCT})\end{array}$ & 364 & rCRCLM & $\begin{array}{l}\text { FOLFOX+Surgery } \\
(182)\end{array}$ & Surgery & OS (61.3 vs. 54.3) \\
\hline Ychou et al (123) & 2009 (RCT) & 305 & rCRCLM & FOLFIRI & $\mathrm{LV} / 5 \mathrm{FU}$ & $\begin{array}{l}\text { DFS ( } 24.7 \text { vs. } 21.6) \\
\text { Higher grade } 3 / 4 \text { toxic } \\
\text { in FOLFIRI } \\
(47 \% \text { vs. } 30 \%)\end{array}$ \\
\hline $\begin{array}{l}\text { Portier } \text { et al } \\
\text { FFCD trial (124) }\end{array}$ & 2006 (RCT) & 173 & rCRCLM & $\begin{array}{l}\text { Surgery+Adjuvant } \\
(86)\end{array}$ & $\begin{array}{l}\text { Surgery } \\
(87)\end{array}$ & $\begin{array}{l}\text { DFS }(33.5 \% \text { vs. } 26.7 \%) \\
P=0.028 \\
\text { OS }(51.1 \% \text { vs. } 41.1 \%) \\
P=0.13\end{array}$ \\
\hline
\end{tabular}

DFS, disease-free survival; FOLFIRI, fluorouracil, leucovorin, irinotecan; LV/5FU, folinic acid (leucovorin)/5-fluorouracil; MCT, muticentric trial; OS, overall survival; PFS, progression-free survival; rCRCLM, resectable colorectal cancer liver metastasis; RCT, randomized controlled trials; wt, wild-type; FOLFOX, 5-FU, lecovorin, oxaliplatin.

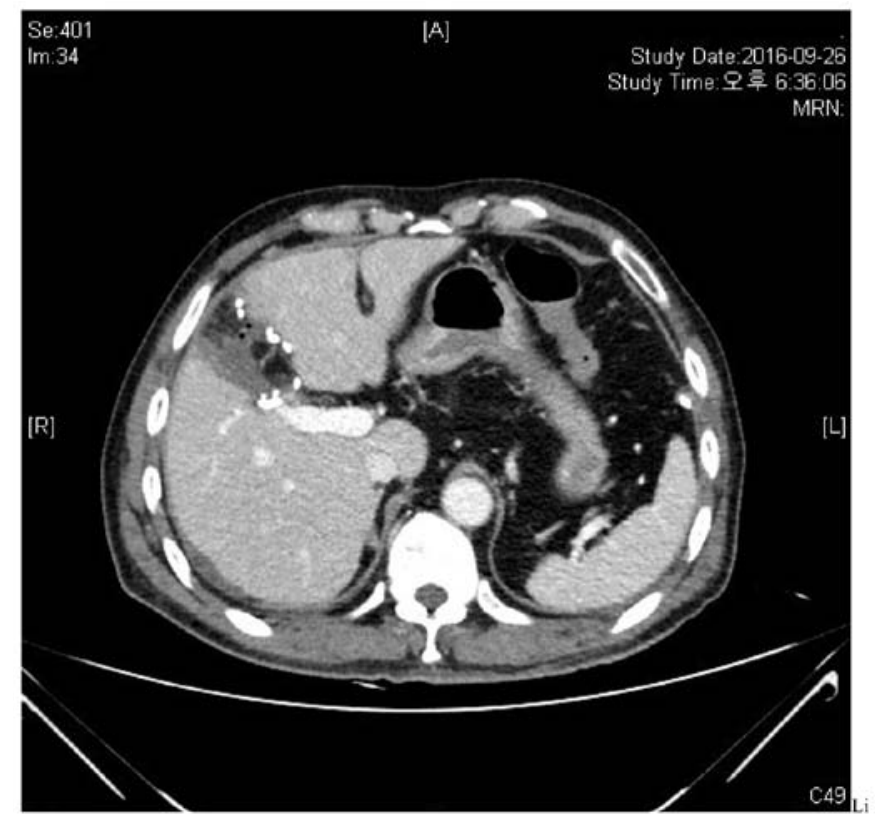

Figure 1. Simultaneous liver and primary resection in a challenging tumor location. Liver metastasis located intra-parenchyma and near portal vein has been resected completely without consequent complications.

Surgical approaches for liver metastasis. Several liver resection techniques exist. Previously, two-stage hepatectomy (TSH) was recommended to reduce surgical trauma (45). However, most cancer centers, including our institution, supported a single-stage approach after finding insignificant morbidity during perioperative management $(46,47)$. However, no existing protocol favor simultaneous resection over a staged approach. The approach depends on the surgeon's experience and patient's physical status. The only possible advantage of single stage over two-stage procedure is the earlier initiation of adjuvant chemotherapy (48). Silberhumer et al (49) studied
429 patients subjected to operative treatment for CRC with simultaneous liver metastases; 75 and 25\% underwent simultaneous and staged resection, respectively. The 1-year survival rates were $90.5 \%$ in the simultaneous group and $92.6 \%$ in the staged group, and the corresponding 5-year survival rates were 38.5 and $38.9 \%$, respectively. Simultaneous liver resection and staged procedures are associated with similar long-term cancer outcomes. We encourage single-stage liver resection together with primary lesion resection whenever possible, as shown in Fig. 1.

Moreover, radical extended lymph node dissection should be considered for suspected lymph nodes in the hepatic pedicle or in patients with $>3$ poorly differentiated metastatic lesions in segments (IV and V) (50). Currently, TSH is considered only if an adequate liver remnant cannot be preserved after HR; TSH and HR; In this case, certain groups of liver tumors are resected first, followed by resection of the remaining tumors in a second procedure after a liver regeneration period (4-12 months) (51). The two-stage procedure is largely used for unresectable liver metastasis or to render unresectable lesions resectable, especially when combined with alternative treatments such as portal vain embolization or RFA (discussed in detail later on).

\section{Synchronous unresectable CRCLM (uCRCLM)}

This common scenario presents a real challenge in the medical field. Whether primary mass resected first to debulk tumor-related complications or upfront chemotherapy should be administered first to downstage the tumor. Numerous treatment procedures are tailored according to the patient's presentation and tumor criteria as follows:

Evolution of chemotherapy in CRCLM. Upfront chemotherapy is the treatment modality of choice for UCRCLM. Appropriate chemotherapy regimens promote tumor downstaging and 
can subsequently render unresectable tumors into resectable (i.e., conversion chemotherapy) $(52,53)$. Previously, singleagent chemotherapy with $5 \mathrm{FU}$ and folinic acid $(5 \mathrm{FU} / \mathrm{LV})$ yielded a response of $20 \%$. A randomized trial (54), allocated 40 patients to receive $5 \mathrm{FU} / \mathrm{LV}$ or placebo, marked improved OS was observed with chemotherapy, compared with placebo (11 months vs. 5 months). Consequently, combined therapy composed of 5FU and oxaliplatin or irinotecan treatment has increased response rates to $40-50 \%$, with estimated median OS durations of 12-20 months $(55,56)$.

Several recent publications have described well-designed phase III trials that evaluated the benefits of oxaliplatin-based chemotherapy particularly in improving pathological response rates (57-61). This conclusion was investigated in a recent meta-analysis by An et al (62), and it confirmed the benefits of oxaliplatin for local and distant metastasis. Furthermore, Zakaria et al (52) examined the application of three chemotherapy agents and tumor responses in 42 patients with uCRCLM; $60 \%$ achieved tumor reduction, $40 \%$ underwent surgery, and the median survival duration was 26 months. However, a high postoperative recurrence rate was observed (73\%). Overall, a combined approach with resection yielded higher resectability rates and higher negative margins for uCRCLM $(63,64)$.

The GERCOR study (65), randomly allocated 109 patients with CRCLM to FOLFIRI as a first-line therapy followed by FOLFOX6; 111 additional patients were assigned to receive FOLFOX6 followed by FOLFIRI. The median survival was equivalent in both arms ( 21.5 vs. 20 months, respectively). However, in FOLFOX arm, 22\% of patients received surgery for liver metastases vs. $9 \%$ in the FOLFIRI arm $(\mathrm{P}=0.02)$. A phase III trial of $5 \mathrm{FU} / \mathrm{LV}$, irinotecan, and oxaliplatin (FOLFIRINOX) indicated an effectively better response but high toxicity (grade 3/4 neutropenia); accordingly, this approach warrants further monitoring (66). We recommend single stage resection in rCRCLM whenever is possible or upfront chemotherapy to assess tumor biology and response in borderline resectability of liver metastasis.

Emerging target agents in liver metastasis. Molecular target agents specific for vascular endothelial growth factor (VEGF) have been developed, including bevacizumab and cetuximab. Saltz et al (67), evaluated the efficacy of adding bevacizumab to oxaliplatin-based chemotherapy [capecitabine plus oxaliplatin (XELOX) or (FOLFOX-4)] in 1401 patients with CRCLM. The median PFS durations were 9.4 months in the bevacizumab group and 8.0 months in the placebo group $(\mathrm{P}=0.0023)$; the groups had similar OS and response rates. In another randomized trial conducted by Bokemeyer et al (68), to evaluate the addition of cetuximab to FOLFOX-4 vs. FOLFOX-4 only, cetuximab was associated with a clinically significant increase in overall response $(61 \%$ vs. $37 \%$; $\mathrm{P}=0.011)$ and reduced risk of disease progression (hazard ratio $=0.57 ; \mathrm{P}=0.0163$ ) when compared with FOLFOX-4 alone, particularly in KRAS wildtype tumors.

Based on these data, we encourage the FOLFOX regimen, in addition to target agents, as a first-line treatment of choice at our institute. Our recent report by Kim et al (69) reviewed 50 patients with locally advanced rectal cancer and borderline-resectable liver metastases. Patients were treated by short-course radiotherapy (SCRT) and upfront chemotherapy (FOLFOX, FOLFIRI, +/- target agent), with delayed surgery. Tumor downstaging and R0 resection were achieved in 35 (70\%) patients. The median PFS was 16 months, and the 2-year PFS rate was $34.8 \%$. Furthermore, chemotherapy can be administered via hepatic arterial infusion (HAI), which yields higher response rates to both first and second-line therapies particularly in oxaliplatin or irinotecan infusion $(70,71)$. Nevertheless, HAI is a technically demanding procedure that should be handled by experts. HAI-based treatment strategies are controversial with regard to procedure-related morbidities such as sclerosing cholangitis and limited experience (72).

Radiotherapy application in CRCLM. Systemic chemotherapy has been widely studied; however, the oncologic outcomes are inconclusive in CRCLM (73). Therefore, current questions are raised whether the radiotherapy dose or pathway could contribute to achieving better results is controversial. A phase II trial (69) evaluated a 12-week FOLFOX regimen with pelvic CRT in 26 patients with symptomatic advanced rectal cancer and metastatic disease. 18F-fluorodeoxyglucose positron emission tomography (FDG-PET) revealed metabolic response rates of $96 \%$ for primary rectal cancer and $60 \%$ for metastatic disease; evidence of good pathological responses was also observed in resected specimens. Of note, the authors of that study invented a new approach at which RT therapy was divided into 2 courses to reduce toxicity. Accordingly, $92 \%$ of the 26 patients reached treatment week 11 without deviation, suggesting positive outcomes of this treatment strategy. The RT formats and strategies will be discussed in the following sections.

Application of SCRT in locally advanced rectal cancer with $u C R C L M$. Application of radiotherapy has widely been used in the field of CRC. In CRCLM, however, SCRT has been proposed along with chemotherapy and delayed surgery, which has yielded a great improvement in controlling the tumor locally. Technique and procedure of SCRT has been previously described in our study (74). Besides, combined approaches of SCRT along with FOLFOX have been validated in several recent studies.

van Dijk et al (4) evaluated SCRT followed by neoadjuvant bevacizumab, capecitabine, and oxaliplatin chemotherapy in 50 patients with CRC metastases. Of these 36 (72\%) patients could undergo surgery. The 2 -year OS rate was $80 \%$. Recently, we proposed a phase II trial (74) of 6 patients diagnosed with uCRCLM and locally advanced rectal cancer. This trial was designed to assess upfront treatment with FOLFOX and SCRT (25 Gy/5 fractions), followed by surgery after a 4-6-week delay. We observed regression of most metastatic lesions and simultaneous rectal tumor downsizing, thus one stage procedure was feasible. Radu et al (75), in accordance with our study conclusion, in 46 patients with unresectable rectal cancer, with or without metastases, received SCRT with delayed surgery. Thirty-seven $(80 \%)$ patients ultimately underwent surgery, and $32(86 \%)$ achieved $\mathrm{R} 0$ resection.

In addition, Yoon et al (76), reported our experience of SCRT in 50 patient diagnosed with locally advanced rectal cancer and synchronous liver metastasis, receiving chemotherapy and 
Table II. Outcomes of short course radiotherapy and delayed surgery in CRCLM.

\begin{tabular}{|c|c|c|c|c|c|c|}
\hline Author & Year & No. & Patient & Study design & Method & Outcome \\
\hline Radu et al (75) & 2008 & 46 & ULARC+LM & Retrospective & SCRT+DS & $\begin{array}{l}\text { Downstaged with high } \\
\text { resectability rate }\end{array}$ \\
\hline Hatfield et al (125) & 2009 & 43 & ULARC & Retrospective & SCRT+DS & $\begin{array}{l}\text { Downstaged, resectable in } \\
61 \% \text {, MS } 44 \text { vs. } 23 \text { months }\end{array}$ \\
\hline Shin et al (74) & 2011 & 6 & $\mathrm{LARC}+\mathrm{LM}$ & Retrospective & FOLFOX+SCRT+DS & $\begin{array}{l}\text { Good overall response, } \\
\text { resectability of all lesion, } \\
\text { no LR for } 16.5 \text { months F/U }\end{array}$ \\
\hline Pettersson et al (126) & 2012 & 112 & ULARC & Retrospective & SCRT+DS & Tumor regression in $74 \%$ \\
\hline Van Dijik et al (4) & 2013 & 50 & LARC+RLM & Phase II trial & SCRT+bev-CapeOx & $\begin{array}{l}\text { The 2-year OS }(80 \%) \text {, } \\
\text { RR }(64 \%), \text { pCR } 26 \%\end{array}$ \\
\hline Kim et al (69) & 2016 & 32 & $\mathrm{LARC}+\mathrm{LM}$ & Phase II trial & mFOLFOX6+SCRT+DS & $\begin{array}{l}\text { Resection of CRCLM } \\
(78 \%), \text { R0 }(63 \%), \\
\text { Down stage }(54 \%), \\
\text { OS (38), PFS (9) months }\end{array}$ \\
\hline
\end{tabular}

MS, median survival; LR, local recurrence; FOLFOX, 5-FU, lecovorin, oxaliplatin; uCRCLM, unresectable colorectal cancer; DS, delay surgery; PFS, progressive-free survival.

delayed surgery. Of these patients, 35 underwent radical surgery for primary and metastatic tumors to achieve therapeutic resection; $13.6 \%$ achieved clinical complete response (CR) of metastases. PFS was longer in the curable group. The 2-year PFS rate was $34.8 \%$. The 2- and 5-year OS rates were 73.9 and $55.1 \%$, respectively. This approach could be an alternative treatment modality in locally advanced rectal cancer with liver metastasis that require further investigation in appropriate clinical trial in the future. Several studies have addressed this aspect and are illustrated in Table II.

\section{Ablative modalities for liver metastasis}

Liver metastases are best eradicated by excision; however, if resection is unsuitable, consensus suggests that combination ablative therapy should be considered to prevent liver failure after major resection. RFA, cryotherapy, or high intensity focused ultrasound, can be used in combination to offer curative treatment in patients with unresectable tumors $(77,78)$. Currently, a phase II randomized extension of the EORTC intergroup randomized study 40004 (CLOCC) (10) has enrolled 119 patients with uCRCLM to investigate the benefit of FOLFOX plus RFA vs. FOLFOX alone. The inclusion criterion was a maximum of 9 liver lesions without extrahepatic involvement. The 30 -month OS rates were $61.7 \%$ in the combination group vs. $57.6 \%$ in the control group. The median OS durations were 45.6 vs. 40.5 months $(\mathrm{P}<0.01)$, thus favoring combination treatment over FOLFOX alone. Abdalla et al (79) reported their experience with RFA vs. chemotherapy alone for CRCLM; the authors observed significant improvements with RFA relative to chemotherapy alone.

Furthermore, combined therapy (resection+RFA) help to achieve a R0 status while maintaining an adequate FLR to avoid postoperative hepatic failure (80). However, surgical decision for RFA should be crucial and tailored accordingly, otherwise may end with unwanted consensus in particular of higher local recurrence rate. Qui et al (81) enrolled 112 patients diagnosed with unresectable liver metastasis from different primary tumors. The ablation success rates were $93.3 \%$ for hepatocellular carcinoma (HCC) and $96.7 \%$ for secondary liver metastasis. The corresponding 5-year overall recurrence rates of these diseases were 80 and $77.8 \%$, respectively. Park et al (82) predicted factors associated with high recurrence rates after RFA in patients with hepatic metastases. Lesions with ablative margins of $\geq 5 \mathrm{~mm}$ were associated with longer disease-free interval than lesions of $<5 \mathrm{~mm}$. These finding are on line with our experience. Hur et al (83) conducted comparative study between HR and RFA in 67 consecutive patients with solitary CRCLM. Forty-two patients underwent HR and 25 patients underwent RFA. The 5-year overall and local recurrence-free survival rates (LRFS) were in favor of HR (50.1 and $89.7 \%$, respectively) and (25.5 and $69.7 \%$, respectively) than RFA, particularly in patients with tumor $>3 \mathrm{~cm}$. However, LRFS was likewise to resection with tumor size $<3 \mathrm{~cm}(95.7 \%$ vs. $85.6 \%, \mathrm{P}=0.304)$. Thus, we recommend selecting appropriate patients and tumor character ahead of planning RFA procedure.

Noteworthy, Mima et al (84) evaluated combined therapy (RFA, hepatic resection HR in patients previously received chemotherapy (FOLFOX \pm bevacizumab) vs. HR alone in a total of 118 patients with uCRCLM. The postoperative morbidity rates were 17 and $23 \%$, respectively $(\mathrm{P}=0.640)$. Local recurrence at the RFA site occurred in only one tumor $(1.6 \%$ per lesion, $7.7 \%$ per patients). The 3-year PFS rates were $45.3 \%$ in the HR group and $12.8 \%$ in the HR+RFA group $(\mathrm{P}=0.472)$. The 3-year OS rates were $70.4 \%$ in the HR group and $77.1 \%$ 
in the HR+RFA group $(\mathrm{P}=0.627)$. These data suggest that in patients previously treated with chemotherapy, a combined approach (RFA+HR) effectively reduces the recurrence rate if used appropriately. Nevertheless, these studies were retrospective, and a randomized controlled trial is needed to delineate the risks and benefits of particular approaches in UCRCLM.

Orientation of RFA limitation and complication is crucial. Berber et al (85) suggested criteria for the prediction of a poor response to RFA treatment; $>3$ liver metastases, a carcinoembryonic antigen (CEA) level $>200 \mathrm{ng} / \mathrm{ml}$, extrahepatic disease, and liver metastasis $>5 \mathrm{~cm}$. In addition, RFA is associated with few complications (e.g., bleeding, infection, bile duct injury) and a stably high local recurrence rate (estimation: 40\%), particularly if performed via percutaneous approach (86). Therefore, intraoperative RFA is an effective and preferred method, although technical precautions are highly warranted. A meta-analysis advocated safety of RFA in liver tumors $<3 \mathrm{~cm}$ in size that may yield lower recurrent rate (87). The lack of well-designed trials currently inhibits comparisons with various other treatment modalities (88). RFA remains an attractive alternative to major HR with both curative and palliative intent, and yields promising results after taking strict precautions for lesions near major biliary or vascular structures (89).

\section{Portal vein embolization (PVE)}

The goal of portal vein embolization (PVE) is to achieve complete portal occlusion of the targeted segments and generate adequate liver hypertrophy prior to a proposed surgery. Preoperative PVE was first described by Elias et al (90) in 14 patients with hilar cholangiocarcinoma, in whom successful results were achieved without major consequences. The Cardiovascular and Interventional Radiological Society of Europe (CIRSE) reported minor and major complications of PVE at 25 and 5\%, respectively (91). However, PVE contraindications should be noted; these include extensive ipsilateral tumor thrombus and clinically evident portal hypertension. However, PVE may be an important component of two-stage hepatectomy, thus rendering unresectable bilateral CRCLM resectable $(92,93)$. Narita et al (94) studied the outcomes of PVE in 80 patients with liver metastasis, among whom 61 had completed twostage hepatectomy. The 5-year OS rate was $32 \%$, and the median OS duration was 39.6 months.

A major drawback of PVE is the risk of tumor growth after embolization, as observed in a previous large observational study. The authors assessed the effects of PVE and bevacizumab on liver hypertrophy and tumor growth to control group (bevacizumab without PVE). Among 119 study patients, significant increases in total tumor volume were observed in the PVE group, whereas decreases were observed in the control arm (0.07 vs. $\left.0.06 \mathrm{~cm}^{3} / \mathrm{day}, \mathrm{P}<0.01\right)$ (95). An animal study by Maggiori et al (96) found that PVE increased tumor growth in the non-occluded liver while decreasing growth in the occluded liver. This tumor growth after PVE was poorly understood, but might be attributable to post-PVE proliferative activity involving increased levels of cytokines and inflammatory mediators (97). Therefore, does PVE jeopardize the downstaging effect of chemotherapy on CRCLM? This debate has not been defined yet. Noteworthy, hepatocyte growth factor (HGF) has been suggested as the major liver and tumor stimulus, as reported by Zou et al (98). Thereafter using of anti-inflammatory medication to ameliorate PVE proliferative activity is a topic of debates.

Emerging of Selective internal radiotherapy (SIRT) contributed to develop the PVE technique. In a meta-analysis (99), SIRT exhibited appropriate usefulness in $90 \%$ of uCRCLM cases. Therefore, a combination of PVE and SIRT could provide a surrogate for major hepatectomy (SIRT will be explained later in this review). However, this combination has not yet been established (100). Remaining controversies surrounding challenges and treatment options suggest that considerable effort will be required in the future to validate the PVE treatment.

\section{Emerging techniques in addressing uCRCLM}

Associating liver partition with PVL for staged hepatectomy (ALPPS). Schnitzbauer et al (101) described a novel approach: associating liver partition and portal vein ligation for staged hepatectomy (ALPPS). This new surgery resulted in a $74 \%$ increase in the volume of the liver remnant in a mean period of 9 days. However, this procedure was associated with a morbidity rate as high as $68 \%$ and a mortality rate as high as $14 \%$. From a technical point of view, standard ALPPS, briefly, has two stages; stage I includes right portal vain ligation (PVL), and in situ splitting of the liver parenchyma along the right side of the falciform ligament. All portals, arterial, and biliary duct of segment IV are identified and divided. Biliary and arterial structures and venous drainage of the right liver are retained. Stage II elected after 1-2 weeks to address targeted plan of right-extended lobectomy and ligating of right hepatic artery, right bile duct, and hepatic vein (101). Procedure illustrated in Fig. 2. Moreover, Gauzolino et al (102) described 3 modified forms of the original ALPPS procedure which are out of our score in this review.

Theory of ALPPS. Honjo et al (103) was the first to introduce PVL similar to those of PVE principles. These methods have been compared with regard to FLR hypertrophy; however, the results were inconclusive $(104,105)$. Recently, a novel two-stage liver resection technique emerged that involves a combination of PVL and ALPPS. ALPPS has been designated superior because it is associated with a rapid, abrupt achievement of FLR hypertrophy (80\% more rapid than PVL or PVE) thus allowing second-stage surgery within 2 weeks (106). This gain in time allows more rapid liver regeneration and a reduced risk of subsequent tumor growth (101).

Trials of ALPPS for CRCLM. ALPPS has enabled to rescue patients with uCRCLM who have failed to achieve adequate FLR after PVE. Nevertheless, this procedure is technically demanding and associated with a high comorbidity rate (40\%) (107). To date, a systemic review and meta-analysis (108) has evaluated three procedures for the treatment of liver tumors: ALPPS, PVE, and PVL. The authors found no significant difference between PVE and PVL in terms of tumor progression or resection rate, whereas ALPPS was associated with a significant increase in FLR. In a 2015 meta-analysis, 


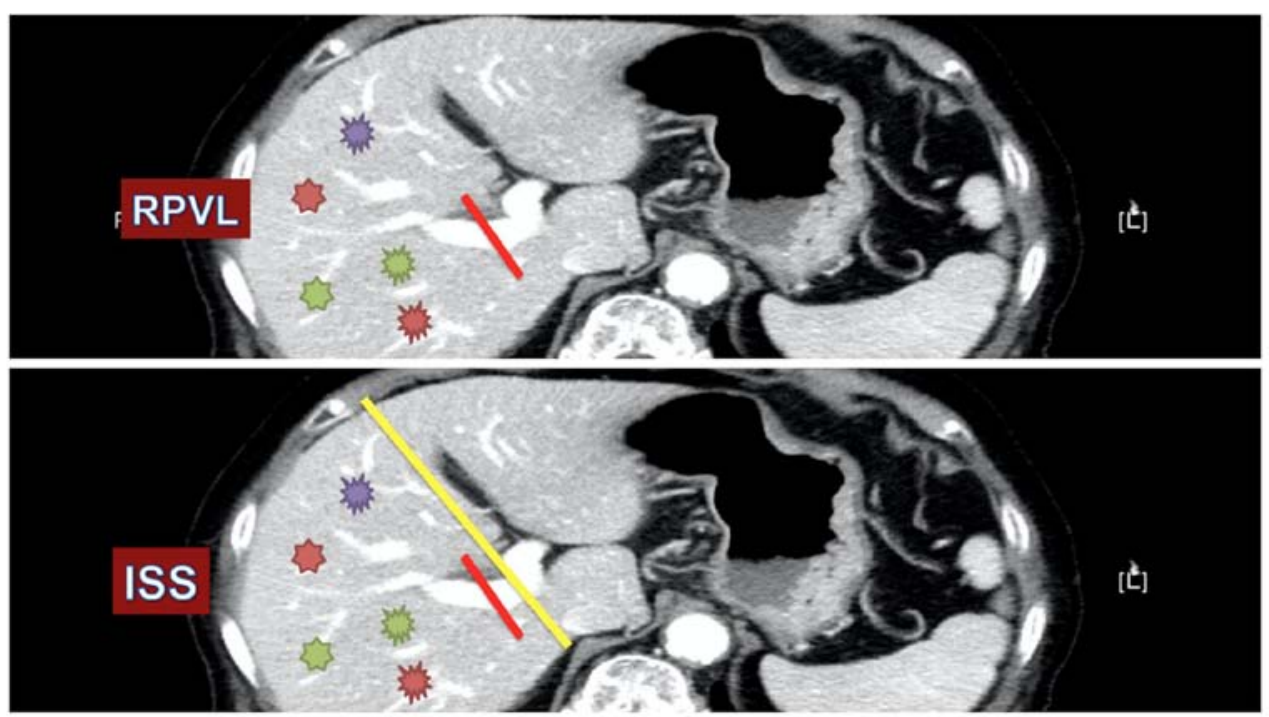

Figure 2. Illustration of associating liver partition and portal vein ligation for staged hepatectomy (ALPPS). Surgical technique of ALPPS started by RPLV (Ligation of right portal vain) and in situ splitting of the liver parenchyma along the right side of the falciform ligament. Thus, liver will obtain sufficient size before planning major hepatic resection.

Table III. Results of new techniques in treating liver metastasis.

\begin{tabular}{|c|c|c|c|c|c|}
\hline Authors & Year & No. (study) & Country & Method & Outcome \\
\hline \multicolumn{6}{|l|}{ SIRT based results } \\
\hline Turkmen et al (127) & 2013 & $61(\mathrm{RS})$ & & $\begin{array}{l}\text { SIRT in liver mets } \\
\text { from different primaries }\end{array}$ & $\begin{array}{l}\text { OS responder }(32.0 \pm 5.6) \\
\text { Non-responder }(11.4 \pm 2.1) \\
(\mathrm{P}=0.054)\end{array}$ \\
\hline Kucuk et al (128) & 2011 & 78 (RS) & & $\begin{array}{l}\text { SIRT in liver mets } \\
\text { from different primaries }\end{array}$ & $55 \%$ responder improve PFS \\
\hline $\begin{array}{l}\text { ALPPS based results } \\
\text { Björnsson et al (129) }\end{array}$ & 2016 & 23 (RS) & Sweden & ALPPS & $\begin{array}{l}\text { Severe complications occurred } \\
\text { in } 13.6 \% \\
\text { One }(4.5 \%) \text { patient died, } 2 \text { year } \\
\text { OS was } 59 \%\end{array}$ \\
\hline Kremer et al (130) & 2015 & 19 (RS) & Germany & $\begin{array}{l}(\mathrm{CTx}+\mathrm{ALPPS}) \\
\text { vs. ALPPS }\end{array}$ & $\begin{array}{l}\text { Increased FLR volume in } \\
\text { non-CTx }(98 \pm 35 \%) \\
\text { Increased FLR volume in CTx } \\
(59 \pm 22 \%),(\mathrm{P}=0.027) \\
\text { CTx impaired FLR hypertrophy }\end{array}$ \\
\hline Torres et al (131) & 2013 & 39 (RS) & Portugal & ALPPS & $\begin{array}{l}\text { Left lateral segment of the liver } \\
\text { increased } 83 \% \\
\text { Morbidity } 59 \text {, Mortality } 12.8 \%\end{array}$ \\
\hline
\end{tabular}

ALPPS, associating liver partition and portal vein ligation for staged hepatectomy; CTx, chemotherapy; FLR, future liver remnant; SIRT, selective internal radiotherapy; OS, overall survival; PFS, progressive-free survival; RS, retrospective study.

Sun et al (109) reported a higher morbidity rate with ALPPS compared with 2 -stage hepatectomy (56.3\% vs. $36.1 \%$, $\mathrm{P}<0.01)$, and a higher resection rate with ALPPS (100\% vs. $79.1 \%$ ). Schadde et al (106) conducted a multicenter study of 320 patients at 55 centers. The reported $75 \%$ mortality rate was attributed to liver failure. Accordingly, appropriate selection for ALPPS is crucial.

Surprisingly, authors argue about the true volume of the FLR following the ALPPS procedure. Tissue edema and inflammatory reactions could affect the post-ALPPS liver 
size, leading to an over measurement relative to the actual total volume of the FLR (110). The recent technique of hepatobiliary scintigraphy can be used to assess total and regional liver function $(111,112)$. Finally, the ALPPS procedure is in an early milestone stage and is associated with a higher morbidity rate than other treatment modalities; however the results remain controversial (113). Notably, the mortality rate associated with ALPPS was $9 \%$, but this decreased to $5 \%$ in a sub-analysis of patients aged $<60$ years who were diagnosed with CRCLM (106). We conclude that ALPPS surgery should be strongly considered, as it yields good outcomes in a subset of patients; however, further evaluation through well-organized trials is required in the future.

\section{Selective internal radiotherapy (SIRT)}

Currently, the new modality for targeting liver lesions emerged in a form of selective internal radiotherapy (SIRT) technique in order to target distal tumor vasculature. Yttriummicrospheres are used for radiotherapy embolization with high energy and parenchyma penetration of $>11 \mathrm{~mm}$, which make it effective in liver metastasis trapped at the distal end of tumor vasculature. SIRT, has been previously shown to yield early successes in patients with HCC (114). Since then, other authors have investigated the applications of SIRT for liver metastasis, regardless of primary tumor, and have obtained good results $(115,116)$. Accordingly, SIRT has been assigned as the treatment of choice for $90 \%$ of uCRCLMs that achieved success after a chemotherapy failure $(99,115)$. Van Hazel et al (117) conducted a randomized clinical trial evaluating the utility of SIRT plus chemotherapy (FU/LV) vs. chemotherapy alone in 11 patients with uCRCLM. The time to disease progression analysis favored the SIRT arm (18.6 months vs. 3.6 months, $\mathrm{P}<0.0005)$. Additionally, the median survival duration was significantly longer in the SIRT arm (29.4 months vs. 12.8 months, $\mathrm{P}=0.02)$.

Noteworthy, in 2016, the novel SIRFLOX trial, conducted by Van Hazel et al (118), assessed the efficacy of SIRT plus mFOLFOX6 plus or minus bevacizumab vs. mFOLFOX6 alone. The authors enrolled 530 patients who were stratified into control (263 patients) and SIRT arms (267 patients). No significant improvement in PFS was observed at any site (control, 10.2 vs. SIRT, 10.7 months); however, SIRT significantly delayed disease progression in the liver only (control, 12.6 vs. SIRT, 20.5 months). The complete response rates were $6 \%$ in the SIRT arm vs. $1.9 \%$ in the control arm $(\mathrm{P}=0.020)$. According to the GERCOR database, the response rate was higher among patients with liver-limited metastases, compared to those with extrahepatic metastases (119).

Despite the promising results of SIRT in CRCLM (120), understanding technical principle is essential to avoid inevitable complication. Particularly if there was vascular variation of gastrodeudenal artery, left gastric artery or presence of arteriovenous fistula that may transmit radiotherapy to forgut or adjacent structure end with serious radiotherapy damage (121). Thus, orientation about vasculature anatomy before initiating SIRT procedure is a crucial point.

Therefore, SIRT is technically demanding, and certain levels of skill and experience are warranted before planning treatment with this procedure. Therefore, SIRT remains in an early milestone stage, and more effort is needed to validate its safety and feasibility in CRCLM. The results of recent trials are listed in Table III.

\section{Conclusion}

Although considerable effort has been expended to improve the outcomes of CRCLM, treatment policies are poorly defined. For resectable CRCLM, systemic chemotherapy regimens, together with liver resection, appear to improve DFS when compared with surgery alone. The OS outcomes, however, have not previously been well illustrated. For uCRCLM, several techniques intended to increase the rate of liver resection have emerged. Still, contradictory data and variable results have contributed to an inability to determine an appropriate conclusion. Furthermore, SIRT and ALPPS procedures are demanding in terms of technical skill and resources, but have yielded promising initial results. Much effort remains with regard to achieving satisfactory treatment strategies in CRCLM.

\section{References}

1. Lykoudis PM, O'Reilly D, Nastos K and Fusai G: Systematic review of surgical management of synchronous colorectal liver metastases. Br J Surg 101: 605-612, 2014.

2. Nordlinger B, Van Cutsem E, Gruenberger T, Glimelius B, Poston G, Rougier P, Sobrero A, Ychou M; European Colorectal Metastases Treatment Group; Sixth International Colorectal Liver Metastases Workshop: Combination of surgery and chemotherapy and the role of targeted agents in the treatment of patients with colorectal liver metastases: Recommendations from an expert panel. Ann Oncol 20: 985-992, 2009.

3. Simmonds PC, Primrose JN, Colquitt JL, Garden OJ, Poston GJ and Rees M: Surgical resection of hepatic metastases from colorectal cancer: A systematic review of published studies. Br J Cancer 94: 982-999, 2006.

4. van Dijk TH, Tamas K, Beukema JC, Beets GL, Gelderblom AJ, de Jong KP, Nagtegaal ID, Rutten HJ, van de Velde CJ, Wiggers T, et al: Evaluation of short-course radiotherapy followed by neoadjuvant bevacizumab, capecitabine, and oxaliplatin and subsequent radical surgical treatment in primary stage IV rectal cancer. Ann Oncol 24: 1762-1769, 2013.

5. Manfredi S, Lepage C, Hatem C, Coatmeur O, Faivre J and Bouvier AM: Epidemiology and management of liver metastases from colorectal cancer. Ann Surg 244: 254-259, 2006.

6. Bozzetti F, Doci R, Bignami P, Morabito A and Gennari L: Patterns of failure following surgical resection of colorectal cancer liver metastases. Rationale for a multimodal approach. Ann Surg 205: 264-270, 1987.

7. Konopke R, Roth J, Volk A, Pistorius S, Folprecht G, Zöphel K, Schuetze C, Laniado M, Saeger HD and Kersting S: Colorectal liver metastases: An update on palliative treatment options. J Gastrointestin Liver Dis 21: 83-91, 2012.

8. Cummings LC, Payes JD and Cooper GS: Survival after hepatic resection in metastatic colorectal cancer: A population-based study. Cancer 109: 718-726, 2007.

9. de Jong MC, Pulitano C, Ribero D, Strub J, Mentha G, Schulick RD, Choti MA, Aldrighetti L, Capussotti L and Pawlik TM: Rates and patterns of recurrence following curative intent surgery for colorectal liver metastasis: An international multi-institutional analysis of 1669 patients. Ann Surg 250: 440-448, 2009.

10. Ruers T, Punt C, Van Coevorden F, Pierie JP, Borel-Rinkes I, Ledermann JA, Poston G, Bechstein W, Lentz MA, Mauer M, et al: Radiofrequency ablation combined with systemic treatment versus systemic treatment alone in patients with non-resectable colorectal liver metastases: a randomized EORTC Intergroup phase II study (EORTC 40004). Ann Oncol 23: 2619-2626, 2012.

11. Edge SB and Compton CC: The American Joint Committee on Cancer: The 7th edition of the AJCC cancer staging manual and the future of TNM. Ann Surg Oncol 17: 1471-1474, 2010. 
12. Mekenkamp LJ, Koopman M, Teerenstra S, van Krieken JH, Mol L, Nagtegaal ID and Punt CJ: Clinicopathological features and outcome in advanced colorectal cancer patients with synchronous vs. metachronous metastases. Br J Cancer 103: 159-164, 2010.

13. Siriwardena AK, Mason JM, Mullamitha S, Hancock HC and Jegatheeswaran S: Management of colorectal cancer presenting with synchronous liver metastases. Nat Rev Clin Oncol 11: 446-459, 2014.

14. Jemal A, Bray F, Center MM, Ferlay J, Ward E and Forman D: Global cancer statistics. CA Cancer J Clin 61: 69-90, 2011.

15. Adam R: Chemotherapy and surgery: new perspectives on the treatment of unresectable liver metastases. Ann Oncol 14 (Suppl 2): ii13-ii16, 2003.

16. Nordlinger B, Van Cutsem E, Rougier P, Köhne CH, Ychou M, Sobrero A, Adam R, Arvidsson D, Carrato A, Georgoulias V, et al: Does chemotherapy prior to liver resection increase the potential for cure in patients with metastatic colorectal cancer? A report from the European Colorectal Metastases Treatment Group. Eur J Cancer 43: 2037-2045, 2007.

17. Nordlinger B, Sorbye H, Glimelius B, Poston GJ, Schlag PM, Rougier P, Bechstein WO, Primrose JN, Walpole ET, Finch-Jones M, et al; EORTC Gastro-Intestinal Tract Cancer Group; Cancer Research UK; Arbeitsgruppe Lebermetastasen und-tumoren in der Chirurgischen Arbeitsgemeinschaft Onkologie (ALM-CAO); Australasian Gastro-Intestinal Trials Group (AGITG); Fédération Francophone de Cancérologie Digestive (FFCD): Perioperative chemotherapy with FOLFOX4 and surgery versus surgery alone for resectable liver metastases from colorectal cancer (EORTC Intergroup trial 40983): A randomised controlled trial. Lancet 371: 1007-1016, 2008.

18. Cunningham D, Humblet Y, Siena S, Khayat D, Bleiberg H, Santoro A, Bets D, Mueser M, Harstrick A, Verslype C, et al: Cetuximab monotherapy and cetuximab plus irinotecan in irinotecan-refractory metastatic colorectal cancer. N Engl J Med 351: 337-345, 2004.

19. Bramhall SR, Gur U, Coldham C, Gunson BK, Mayer AD, McMaster P, Candinas D, Buckels JA and Mirza DF: Liver resection for colorectal metastases. Ann R Coll Surg Engl 85: 334-339, 2003.

20. Clavien PA, Petrowsky H, DeOliveira ML and Graf R: Strategies for safer liver surgery and partial liver transplantation. N Engl J Med 356: 1545-1559, 2007.

21. Hou W and Zhu X: Extra vascular interventional treatment of liver cancer, present and future. Drug Discov Ther 9: 335-341, 2015.

22. van Dam RM, Lodewick TM, van den Broek MA, de Jong MC, Greve JW, Jansen RL, Bemelmans MH, Neumann UP, Olde Damink SW and Dejong CH: Outcomes of extended versus limited indications for patients undergoing a liver resection for colorectal cancer liver metastases. HPB (Oxford) 16: 550-559, 2014.

23. Vauthey JN, Pawlik TM, Abdalla EK, Arens JF, Nemr RA, Wei SH, Kennamer DL, Ellis LM and Curley SA: Is extended hepatectomy for hepatobiliary malignancy justified? Ann Surg 239: 722-730, discussion 730-732, 2004

24. Tsoulfas G, Pramateftakis MG and Kanellos I: Surgical treatment of hepatic metastases from colorectal cancer. World J Gastrointest Oncol 3: 1-9, 2011

25. Pawlik TM, Abdalla EK, Ellis LM, Vauthey JN and Curley SA. Debunking dogma: Surgery for four or more colorectal liver metastases is justified. J Gastrointest Surg 10: 240-248, 2006.

26. Altendorf-Hofmann A and Scheele J: A critical review of the major indicators of prognosis after resection of hepatic metastases from colorectal carcinoma. Surg Oncol Clin N Am 12: 165-192, xi, 2003.

27. Pulitanò $\mathrm{C}$, Bodingbauer $\mathrm{M}$, Aldrighetti L, de Jong MC, Castillo F, Schulick RD, Parks RW, Choti MA, Wigmore SJ, Gruenberger T, et al: Liver resection for colorectal metastases in presence of extrahepatic disease: Results from an international multi-institutional analysis. Ann Surg Oncol 18: 1380-1388, 2011.

28. Mattar RE, Al-Alem F, Simoneau E and Hassanain M Preoperative selection of patients with colorectal cancer liver metastasis for hepatic resection. World J Gastroenterol 22: $567-581,2016$

29. Abdalla EK, Denys A, Chevalier P, Nemr RA and Vauthey JN: Total and segmental liver volume variations: Implications for liver surgery. Surgery 135: 404-410, 2004.
30. Chang GJ: Challenge of primary tumor management in patients with stage IV colorectal cancer. J Clin Oncol 30: 3165-3166, 2012.

31. Choti MA, Sitzmann JV, Tiburi MF, Sumetchotimetha W, Rangsin R, Schulick RD, Lillemoe KD, Yeo CJ and Cameron JL: Trends in long-term survival following liver resection for hepatic colorectal metastases. Ann Surg 235: 759-766, 2002.

32. Fong Y, Fortner J, Sun RL, Brennan MF and Blumgart LH: Clinical score for predicting recurrence after hepatic resection for metastatic colorectal cancer: Analysis of 1001 consecutive cases. Ann Surg 230: 309-318, discussion 318-321, 1999.

33. Kemeny N, Kemeny MM and Lawrence TS: Liver metastases. In: Clinical Oncology. Abeloff MD, Armitage JO, Lichter AS and Niederhuber JE (eds). Churchill Livingstone, New York, pp886-921, 2000.

34. National Comprehensive Cancer Network: Colon cancer guidelines version 3, 2012; (28/9/2014). Available from: http:// Www.nccn.org/professionals/physician_gls/pdf/colorectal_ screening.pdf.

35. Bai H, Huangz X, Jing L, Zeng Q and Han L: The effect of radiofrequency ablation vs. liver resection on survival outcome of colorectal liver metastases (CRLM): A meta-analysis. Hepatogastroenterology 62: 373-377, 2015.

36. Gruenberger Th, Gruenberger B, Becherer A, Kettenbach J, Dieckmann K and Schima W: Interdisciplinary management of colorectal cancer liver metastases. Eur Surg 38: 107-111, 2006.

37. Viganò L, Capussotti L, De Rosa G, De Saussure WO, Mentha G and Rubbia-Brandt L: Liver resection for colorectal metastases after chemotherapy: Impact of chemotherapy-related liver injuries, pathological tumor response, and micrometastases on long-term survival. Ann Surg 258: 731-742, 2013.

38. Adam R, Pascal G, Castaing D, Azoulay D, Delvart V, Paule B, Levi $\mathrm{F}$ and Bismuth $\mathrm{H}$ : Tumor progression while on chemotherapy: A contraindication to liver resection for multiple colorectal metastases? Ann Surg 240: 1052-1064, 2004

39. Gruenberger B, Scheithauer W, Punzengruber R, Zielinski C, Tamandl D and Gruenberger T: Importance of response to neoadjuvant chemotherapy in potentially curable colorectal cancer liver metastases. BMC Cancer 8: 120, 2008.

40. Khan AZ, Morris-Stiff G and Makuuchi M: Patterns of chemotherapy-induced hepatic injury and their implications for patients undergoing liver resection for colorectal liver metastases. J Hepatobiliary Pancreat Surg 16: 137-144, 2009.

41. Aloia T, Sebagh M, Plasse M, Karam V, Lévi F, Giacchetti S, Azoulay D, Bismuth H, Castaing D and Adam R: Liver histology and surgical outcomes after preoperative chemotherapy with fluorouracil plus oxaliplatin in colorectal cancer liver metastases. J Clin Oncol 24: 4983-4990, 2006.

42. Pulitanò C, Aldrighetti L, Arru M, Vitali G, Ronzoni M, Catena M, Finazzi R, Villa E and Ferla G: Influence of preoperative chemotherapy on the risk of major hepatectomy for colorectal liver metastases. Ann Surg 244: 833-835, author reply 835,2006

43. Khoo E, O'Neill S, Brown E, Wigmore SJ and Harrison EM: Systematic review of systemic adjuvant, neoadjuvant and perioperative chemotherapy for resectable colorectal-liver metastases. HPB (Oxford) 18: 485-493, 2016.

44. Primrose J, Falk S, Finch-Jones M, Valle J, O'Reilly D, Siriwardena A, Hornbuckle J, Peterson M, Rees M, Iveson T, et al: Systemic chemotherapy with or without cetuximab in patients with resectable colorectal liver metastasis: The New EPOC randomised controlled trial. Lancet Oncol 15: 601-611, 2014.

45. Fujita S, Akasu T and Moriya Y: Resection of synchronous liver metastases from colorectal cancer. Jpn J Clin Oncol 30: 7-11, 2000.

46. Tanaka K, Shimada H, Matsuo K, Nagano Y, Endo I, Sekido H and Togo S: Outcome after simultaneous colorectal and hepatic resection for colorectal cancer with synchronous metastases. Surgery 136: 650-659, 2004.

47. Martin R, Paty P, Fong Y, Grace A, Cohen A, DeMatteo R, Jarnagin W and Blumgart L: Simultaneous liver and colorectal resections are safe for synchronous colorectal liver metastasis. J Am Coll Surg 197: 233-241, discussion 241-242, 2003.

48. Chua HK, Sondenaa K, Tsiotos GG, Larson DR, Wolff BG and Nagorney DM: Concurrent vs. staged colectomy and hepatectomy for primary colorectal cancer with synchronous hepatic metastases. Dis Colon Rectum 47: 1310-1316, 2004. 
49. Silberhumer GR, Paty PB, Denton B, Guillem J, Gonen M, Araujo RL, Nash GM, Temple LK, Allen PJ, DeMatteo RP, et al: Long-term oncologic outcomes for simultaneous resection of synchronous metastatic liver and primary colorectal cancer. Surgery 160: 67-73, 2016

50. Jaeck D and Pessaux P: Bilobar colorectal liver metastases: Treatment options. Surg Oncol Clin N Am 17: 553-568, ix, 2008

51. Sharma S, Camci C and Jabbour N: Management of hepatic metastasis from colorectal cancers: An update. J Hepatobiliary Pancreat Surg 15: 570-580, 2008.

52. Zakaria S, Donohue JH, Que FG, Farnell MB, Schleck CD Ilstrup DM and Nagorney DM: Hepatic resection for colorectal metastases: Value for risk scoring systems? Ann Surg 246: 183-191, 2007.

53. Leonard GD, Brenner B and Kemeny NE: Neoadjuvant chemotherapy before liver resection for patients with unresectable liver metastases from colorectal carcinoma. J Clin Oncol 23: 2038-2048, 2005.

54. Scheithauer W, Rosen H, Kornek GV, Sebesta C and Depisch D Randomised comparison of combination chemotherapy plus supportive care with supportive care alone in patients with metastatic colorectal cancer. BMJ 306: 752-755, 1993.

55. Saltz LB, Cox JV, Blanke C, Rosen LS, Fehrenbacher L, Moore MJ, Maroun JA, Ackland SP, Locker PK, Pirotta N, et al; Irinotecan Study Group: Irinotecan plus fluorouracil and leucovorin for metastatic colorectal cancer. N Engl J Med 343: 905-914, 2000

56. de Gramont A, Figer A, Seymour M, Homerin M, Hmissi A, Cassidy J, Boni C, Cortes-Funes H, Cervantes A, Freyer G, et al: Leucovorin and fluorouracil with or without oxaliplatin as firstline treatment in advanced colorectal cancer. J Clin Oncol 18 2938-2947, 2000.

57. Aschele C, Cionini L, Lonardi S, Pinto C, Cordio S, Rosati G, Artale S, Tagliagambe A, Ambrosini G, Rosetti P, et al: Primary tumor response to preoperative chemoradiation with or without oxaliplatin in locally advanced rectal cancer: Pathologic results of the STAR-01 randomized phase III trial. J Clin Oncol 29: 2773-2780, 2011

58. Rödel C, Liersch T, Becker H, Fietkau R, Hohenberger W, Hothorn T, Graeven U, Arnold D, Lang-Welzenbach M, Raab HR, et al; German Rectal Cancer Study Group: Preoperative chemoradiotherapy and postoperative chemotherapy with fluorouracil and oxaliplatin versus fluorouracil alone in locally advanced rectal cancer: Initial results of the German CAO/ARO/AIO-04 randomised phase 3 trial. Lancet Oncol 13: 679-687, 2012.

59. Allegra CJ, Yothers G, O'Connell MJ, Beart RW, Wozniak TF, Pitot HC, Shields AF, Landry JC, Ryan DP, Arora A, et al: Neoadjuvant 5-FU or capecitabine plus radiation with or without oxaliplatin in rectal cancer patients: A phase III randomized clinical trial. J Natl Cancer Inst 107: pii: djv248, 2015.

60. Schmoll H-J, Haustermans K, Price TJ, Nordlinger B, Hofheinz R, Daisne J-F, Janssens J, Brenner B, Schmidt P, Reinel $\mathrm{H}$, et al: Preoperative chemoradiotherapy and postoperative chemotherapy with capecitabine and oxaliplatin versus capecitabine alone in locally advanced rectal cancer: First results of the PETACC-6 randomized phase III trial. J Clin Oncol 31 (Suppl): 3531, 2013

61. Gérard JP, Azria D, Gourgou-Bourgade S, Martel-Laffay I, Hennequin C, Etienne PL, Vendrely V, François E, de La Roche G, Bouché O, et al: Comparison of two neoadjuvant chemoradiotherapy regimens for locally advanced rectal cancer: Results of the phase III trial ACCORD 12/0405-Prodige 2. J Clin Oncol 28: 1638-1644, 2010.

62. An X, Lin X, Wang FH, Goodman K, Cai PQ, Kong LH, Fang YJ, Gao YH, Lin JZ, Wan DS, et al: Short term results of neoadjuvant chemoradiotherapy with fluoropyrimidine alone or in combination with oxaliplatin in locally advanced rectal cancer: A meta analysis. Eur J Cancer 49: 843-851, 2013.

63. Razafindratsira T, Isambert $\mathrm{M}$ and Evrard S: Complications of intraoperative radiofrequency ablation of liver metastases. HPB (Oxford) 13: 15-23, 2011.

64. Evrard S, Rivoire M, Arnaud J, Lermite E, Bellera C, Fonck M, Becouarn Y, Lalet C, Puildo M and Mathoulin-Pelissier S: Unresectable colorectal cancer liver metastases treated by intraoperative radiofrequency ablation with or without resection. Br J Surg 99: 558-565, 2012

65. Tournigand C, André T, Achille E, Lledo G, Flesh M, MeryMignard D, Quinaux E, Couteau C, Buyse M, Ganem G, et al: FOLFIRI followed by FOLFOX6 or the reverse sequence in advanced colorectal cancer: A randomized GERCOR study. J Clin Oncol 22: 229-237, 2004.
66. Falcone A, Ricci S, Brunetti I, Pfanner E, Allegrini G, Barbara C, Crinò L, Benedetti G, Evangelista W, Fanchini L, et al; Gruppo Oncologico Nord Ovest: Phase III trial of infusional fluorouracil leucovorin, oxaliplatin, and irinotecan (FOLFOXIRI) compared with infusional fluorouracil, leucovorin, and irinotecan (FOLFIRI) as first-line treatment for metastatic colorectal cancer: The Gruppo Oncologico Nord Ovest. J Clin Oncol 25: 1670-1676, 2007.

67. Saltz LB, Clarke S, Díaz-Rubio E, Scheithauer W, Figer A, Wong R, Koski S, Lichinitser M, Yang TS, Rivera F, et al: Bevacizumab in combination with oxaliplatin-based chemotherapy as first-line therapy in metastatic colorectal cancer: A randomized phase III study. J Clin Oncol 26: 2013-2019, 2008.

68. Bokemeyer C, Bondarenko I, Makhson A, Hartmann JT, Aparicio J, de Braud F, Donea S, Ludwig H, Schuch G, Stroh C, et al: Fluorouracil, leucovorin, and oxaliplatin with and without cetuximab in the first-line treatment of metastatic colorectal cancer. J Clin Oncol 27: 663-671, 2009.

69. Kim KH, Shin SJ, Cho MS, Ahn JB, Jung M, Kim TI, Park YS, Kim H, Kim NK and Koom WS: A phase II study of preoperative mFOLFOX6 with short-course radiotherapy in patients with locally advanced rectal cancer and liver-only metastasis. Radiother Oncol 118: 369-374, 2016.

70. Grothey A, Jordan K, Kellner O, Constantin C, Dietrich G, Kroening H, Mantovani L, Schlichting C, Forstbauer H and Schmoll H-J: Capecitabine/irinotecan (Capiri) and capecitabine/ oxaliplatin (CapOx) are active second-line protocols in patients with advanced colorectal cancer (ACRC) after failure of first-line combination therapy: results of a randomized phase II study. J Clin Oncol 22 (Suppl 14): 3534, 2004

71. Shimonov M, Hayat H, Chaitchik S, Brener J, Schachter P and Czerniak A: Combined systemic chronotherapy and hepatic artery infusion for the treatment of metastatic colorectal cancer confined to the liver. Chemotherapy 51: 111-115, 2005.

72. Kelly RJ, Kemeny NE and Leonard GD: Current strategies using hepatic arterial infusion chemotherapy for the treatment of colorectal cancer. Clin Colorectal Cancer 5: 166-174, 2005.

73. Lévi F, Giacchetti S, Adam R, Zidani R, Metzger G and Misset JL: Chronomodulation of chemotherapy against metastatic colorectal cancer. Eur J Cancer 31A: 1264-1270, 1995.

74. Shin SJ, Yoon HI, Kim NK, Lee KY, Min BS, Ahn JB, Keum KC and Koom WS: Upfront systemic chemotherapy and preoperative short-course radiotherapy with delayed surgery for locally advanced rectal cancer with distant metastases. Radiat Oncol 6: 99, 2011.

75. Radu C, Berglund A, Påhlman L and Glimelius B: Short-course preoperative radiotherapy with delayed surgery in rectal cancera retrospective study. Radiother Oncol 87: 343-349, 2008.

76. Yoon HI, Koom WS, Kim TH, Ahn JB, Jung M, Kim TI, Kim H, Shin SJ and Kim NK: Upfront systemic chemotherapy and shortcourse radiotherapy with delayed surgery for locally advanced rectal cancer with distant metastases: Outcomes, compliance, and favorable prognostic factors. PLoS One 11: e0161475, 2016.

77. Brooks AJ, Wang F, Alfredson M, Yan TD and Morris DL: Synchronous liver resection and cryotherapy for colorectal metastases: survival analysis. Surgeon 3: 265-268, 2005.

78. Kennedy JE, Wu F, ter Haar GR, Gleeson FV, Phillips RR, Middleton MR and Cranston D: High-intensity focused ultrasound for the treatment of liver tumours. Ultrasonics 42 : 931-935, 2004

79. Abdalla EK, Vauthey JN, Ellis LM, Ellis V, Pollock R, Broglio KR, Hess K and Curley SA: Recurrence and outcomes following hepatic resection, radiofrequency ablation, and combined resection/ablation for colorectal liver metastases. Ann Surg 239: 818-827, 2004.

80. Khatri VP, Chee KG and Petrelli NJ: Modern multimodality approach to hepatic colorectal metastases: Solutions and controversies. Surg Oncol 16: 71-83, 2007.

81. Qiu J, Chen S and Wu H: Long-term outcomes after hepatic resection combined with radiofrequency ablation for initially unresectable multiple and bilobar liver malignancies. J Surg Res 188: 14-20, 2014.

82. Park MJ, Kim TH, Lee KM, Cheong JY and Kim JK: Radiofrequency ablation of metastatic liver masses: Recurrence patterns and prognostic factors based on radiologic features. Hepatogastroenterology 60: 563-567, 2013.

83. Hur H, Ko YT, Min BS, Kim KS, Choi JS, Sohn SK, Cho CH, Ko HK, Lee JT and Kim NK: Comparative study of resection and radiofrequency ablation in the treatment of solitary colorectal liver metastases. Am J Surg 197: 728-736, 2009. 
84. Mima K, Beppu T, Chikamoto A, Miyamoto Y, Nakagawa S, Kuroki H, Okabe H, Hayashi H, Sakamoto Y, Watanabe M, et al: Hepatic resection combined with radiofrequency ablation for initially unresectable colorectal liver metastases after effective chemotherapy is a safe procedure with a low incidence of local recurrence. Int J Clin Oncol 18: 847-855, 2013.

85. Berber E, Pelley R and Siperstein AE: Predictors of survival after radiofrequency thermal ablation of colorectal cancer metastases to the liver: A prospective study. J Clin Oncol 23: 1358-1364, 2005.

86. Solbiati L, Livraghi T, Goldberg SN, Ierace T, Meloni F, Dellanoce M, Cova L, Halpern EF and Gazelle GS: Percutaneous radio-frequency ablation of hepatic metastases from colorectal cancer: Long-term results in 117 patients. Radiology 221: 159-166, 2001.

87. Mulier S, Ni Y, Jamart J, Ruers T, Marchal G and Michel L: Local recurrence after hepatic radiofrequency coagulation: Multivariate meta-analysis and review of contributing factors. Ann Surg 242: 158-171, 2005.

88. Cirocchi R, Trastulli S, Boselli C, Montedori A, Cavaliere D, Parisi A, Noya G and Abraha I: Radiofrequency ablation in the treatment of liver metastases from colorectal cancer. Cochrane Database Syst Rev 6: CD006317, 2012.

89. Bipat S, van Leeuwen MS, Comans EF, Pijl ME, Bossuyt PM, Zwinderman $\mathrm{AH}$ and Stoker J: Colorectal liver metastases: CT, MR imaging, and PET for diagnosis - meta-analysis. Radiology 237: 123-131, 2005.

90. Elias D, De Baere T, Roche A, Mducreux, Leclere J and Lasser P: During liver regeneration following right portal embolization the growth rate of liver metastases is more rapid than that of the liver parenchyma. Br J Surg 86: 784-788, 1999.

91. Denys A, Bize P, Demartines N, Deschamps F and De Baere T; Cardiovascular and Interventional Radiological Society of Europe: Quality improvement for portal vein embolization. Cardiovasc Intervent Radiol 33: 452-456, 2010.

92. Abdalla EK, Bauer TW, Chun YS, D'Angelica M, Kooby DA and Jarnagin WR: Locoregional surgical and interventional therapies for advanced colorectal cancer liver metastases: expert consensus statements. HPB (Oxford) 15: 119-130, 2013.

93. Brouquet A, Abdalla EK, Kopetz S, Garrett CR, Overman MJ, Eng C, Andreou A, Loyer EM, Madoff DC, Curley SA, et al: High survival rate after two-stage resection of advanced colorectal liver metastases: Response-based selection and complete resection define outcome. J Clin Oncol 29: 1083-1090, 2011.

94. Narita M, Oussoultzoglou E, Jaeck D, Fuchschuber P, Rosso E, Pessaux P, Marzano E and Bachellier P: Two-stage hepatectomy for multiple bilobar colorectal liver metastases. Br J Surg 98: 1463-1475, 2011.

95. Simoneau E, Aljiffry M, Salman A, Abualhassan N, Cabrera T, Valenti D, El Baage A, Jamal M, Kavan P, Al-Abbad S, et al: Portal vein embolization stimulates tumour growth in patients with colorectal cancer liver metastases. HPB (Oxford) 14 461-468, 2012.

96. Maggiori L, Bretagnol F, Sibert A, Paradis V, Vilgrain V and Panis Y: Selective portal vein ligation and embolization induce different tumoral responses in the rat liver. Surgery 149: 496-503, 2011.

97. Pamecha V, Levene A, Grillo F, Woodward N, Dhillon A and Davidson BR: Effect of portal vein embolisation on the growth rate of colorectal liver metastases. Br J Cancer 100: 617-622, 2009.

98.Zou RH, Li AH, Han F, Hong J, Li BK, Huang W, Huang L and Yuan YF: Liver hypertrophy and accelerated growth of implanted tumors in nonembolized liver of rabbit after left portal vein embolization. J Surg Res 178: 255-263, 2012.

99. Vente MA, Wondergem M, van der Tweel I, van den Bosch MA, Zonnenberg BA, Lam MG, van Het Schip AD and Nijsen JF: Yttrium-90 microsphere radioembolization for the treatment of liver malignancies: A structured meta-analysis. Eur Radiol 19: 951-959, 2009.

100.de Graaf W, van den Esschert JW, van Lienden KP and van Gulik TM: Induction of tumor growth after preoperative portal vein embolization: Is it a real problem? Ann Surg Oncol 16: 423-430, 2009.

101. Schnitzbauer AA, Lang SA, Goessmann H, Nadalin S, Baumgart J, Farkas SA, Fichtner-Feigl S, Lorf T, Goralcyk A, Hörbelt R, et al: Right portal vein ligation combined with in situ splitting induces rapid left lateral liver lobe hypertrophy enabling 2-staged extended right hepatic resection in small-forsize settings. Ann Surg 255: 405-414, 2012.
102. Gauzolino R, Castagnet M, Blanleuil ML and Richer JP: The ALPPS technique for bilateral colorectal metastases: Three 'variations on a theme'. Updates Surg 65: 141-148, 2013.

103. Honjo I, Suzuki T, Ozawa K, Takasan H, Kitamura O and Ishikawa T: Ligation of a branch of the portal vein for carcinoma of the liver. Am J Surg 130: 296-302, 1975.

104. Aussilhou B, Lesurtel M, Sauvanet A, Farges O, Dokmak S, Goasguen N, Sibert A, Vilgrain V and Belghiti J: Right portal vein ligation is as efficient as portal vein embolization to induce hypertrophy of the left liver remnant. J Gastrointest Surg 12: 297-303, 2008

105. Robles R, Marín C, Lopez-Conesa A, Capel A, Perez-Flores D and Parrilla P: Comparative study of right portal vein ligation versus embolisation for induction of hypertrophy in two-stage hepatectomy for multiple bilateral colorectal liver metastases. Eur J Surg Oncol 38: 586-593, 2012.

106. Schadde E, Raptis DA, Schnitzbauer AA, Ardiles V, Tschuor C, Lesurtel M, Abdalla EK, Hernandez-Alejandro R, Jovine E, Machado M, et al: Prediction of mortality after ALPPS Stage-1: An analysis of 320 patients from the International ALPPS Registry. Ann Surg 262: 780-786, 2015.

107. Shindoh J, Vauthey JN, Zimmitti G, Curley SA, Huang SY, Mahvash A, Gupta S, Wallace MJ and Aloia TA: Analysis of the efficacy of portal vein embolization for patients with extensive liver malignancy and very low future liver remnant volume, including a comparison with the associating liver partition with portal vein ligation for staged hepatectomy approach. J Am Coll Surg 217: 126-134, 2013.

108. Pandanaboyana S, Bell R, Hidalgo E, Toogood G, Prasad KR, Bartlett A and Lodge JP: A systematic review and meta-analysis of portal vein ligation versus portal vein embolization for elective liver resection. Surgery 157: 690-698, 2015.

109. Sun Z, Tang W, Sakamoto Y, Hasegawa K and Kokudo N: A systematic review and meta-analysis of feasibility, safety and efficacy of associating liver partition and portal vein ligation for staged hepatectomy (ALPPS) versus two-stage hepatectomy (TSH). Biosci Trends 9: 284-288, 2015.

110. Shteyer E, Liao Y, Muglia LJ, Hruz PW and Rudnick DA: Disruption of hepatic adipogenesis is associated with impaired liver regeneration in mice. Hepatology 40: 1322-1332, 2004.

111. Hoekstra LT, de Graaf W, Nibourg GA, Heger M, Bennink RJ, Stieger B and van Gulik TM: Physiological and biochemical basis of clinical liver function tests: A review. Ann Surg 257: 27-36, 2013

112. Guiu B, Bize P, Gunthern D, Demartines N, Halkic N and Denys A: Portal vein embolization before right hepatectomy: Improved results using n-butyl-cyanoacrylate compared to microparticles plus coils. Cardiovasc Intervent Radiol 36: 1306-1312, 2013.

113. Eshmuminov D, Raptis DA, Linecker M, Wirsching A, Lesurtel $\mathrm{M}$ and Clavien PA: Meta-analysis of associating liver partition with portal vein ligation and portal vein occlusion for two-stage hepatectomy. Br J Surg 103: 1768-1782, 2016.

114. Lau WY, Ho S, Leung TW, Chan M, Ho R, Johnson PJ and Li AK: Selective internal radiation therapy for nonresectable hepatocellular carcinoma with intraarterial infusion of 90yttrium microspheres. Int J Radiat Oncol Biol Phys 40: 583-592, 1998.

115. Murthy R, Xiong H, Nunez R, Cohen AC, Barron B, Szklaruk J, Madoff DC, Gupta S, Wallace MJ, Ahrar K, et al: Yttrium 90 resin microspheres for the treatment of unresectable colorectal hepatic metastases after failure of multiple chemotherapy regimens: Preliminary results. J Vasc Interv Radiol 16: 937-945, 2005.

116. Welsh JS, Kennedy AS and Thomadsen B: Selective Internal Radiation Therapy (SIRT) for liver metastases secondary to colorectal adenocarcinoma. Int J Radiat Oncol Biol Phys 66 (Suppl): S62-S73, 2006.

117. Van Hazel G, Blackwell A, Anderson J, Price D, Moroz P, Bower G, Cardaci G and Gray B: Randomised phase 2 trial of SIR-Spheres plus fluorouracil/leucovorin chemotherapy versus fluorouracil/leucovorin chemotherapy alone in advanced colorectal cancer. J Surg Oncol 88: 78-85, 2004.

118. Van Hazel GA, Heinemann V, Sharma NK, Findlay MP, Ricke J, Peeters M, Perez D, Robinson BA, Strickland AH, Ferguson T, et al: SIRFLOX: Randomized phase III trial comparing first-line mFOLFOX6 (plus or minus bevacizumab) versus mFOLFOX6 (plus or minus bevacizumab) plus selective internal radiation therapy in patients with metastatic colorectal cancer. J Clin Oncol 34: 1723-1731, 2016. 
119. Bokemeyer C, Van Cutsem E, Rougier P, Ciardiello F, Heeger S, Schlichting M, Celik I and Köhne CH: Addition of cetuximab to chemotherapy as first-line treatment for KRAS wild-type metastatic colorectal cancer: Pooled analysis of the CRYSTAL and OPUS randomised clinical trials. Eur J Cancer 48: 1466-1475, 2012 .

120. Sharma RA, Van Hazel GA, Morgan B, Berry DP, Blanshard K, Price D, Bower G, Shannon JA, Gibbs P and Steward WP: Radioembolization of liver metastases from colorectal cancer using yttrium-90 microspheres with concomitant systemic oxaliplatin, fluorouracil, and leucovorin chemotherapy. J Clin Oncol 25: 1099-1106, 2007.

121. Stubbs RS and Wickremesekera SK: Selective internal radiation therapy (SIRT): A new modality for treating patients with colorectal liver metastases. HPB (Oxford) 6: 133-139, 2004.

122. Nordlinger B, Sorbye H, Glimelius B, Poston GJ, Schlag PM, Rougier P, Bechstein WO, Primrose JN, Walpole ET, Finch-Jones M, et al; EORTC Gastro-Intestinal Tract Cancer Group; Cancer Research UK; Arbeitsgruppe Lebermetastasen und-tumoren in der Chirurgischen Arbeitsgemeinschaft Onkologie (ALM-CAO); Australasian Gastro-Intestinal Trials Group (AGITG); Fédération Francophone de Cancérologie Digestive (FFCD): Perioperative FOLFOX4 chemotherapy and surgery versus surgery alone for resectable liver metastases from colorectal cancer (EORTC 40983): Long-term results of a randomised, controlled, phase 3 trial. Lancet Oncol 14: 1208-1215, 2013.

123. Ychou M, Hohenberger W, Thezenas S, Navarro M, Maurel J, Bokemeyer C, Shacham-Shmueli E, Rivera F, Kwok-Keung Choi C and Santoro A: A randomized phase III study comparing adjuvant 5-fluorouracil/folinic acid with FOLFIRI in patients following complete resection of liver metastases from colorectal cancer. Ann Oncol 20: 1964-1970, 2009.

124. Portier G, Elias D, Bouche O, Rougier P, Bosset JF, Saric J, Belghiti J, Piedbois P, Guimbaud R, Nordlinger B, et al: Multicenter randomized trial of adjuvant fluorouracil and folinic acid compared with surgery alone after resection of colorecta liver metastases: FFCD ACHBTH AURC 9002 trial. J Clin Oncol 24: 4976-4982, 2006.
125. Hatfield P, Hingorani M, Radhakrishna G, Cooper R, Melcher A, Crellin A, Kwok-Williams M and Sebag-Montefiore D: Shortcourse radiotherapy, with elective delay prior to surgery, in patients with unresectable rectal cancer who have poor performance status or significant co-morbidity. Radiother Oncol 92: 210-214, 2009

126. Pettersson D, Holm T, Iversen H, Blomqvist L, Glimelius B and Martling A: Preoperative short-course radiotherapy with delayed surgery in primary rectal cancer. Br J Surg 99: 577-583, 2012 .

127. Turkmen C, Ucar A, Poyanli A, Vatankulu B, Ozkan G, Basaran M, Serin K, Sanli Y and Adalet I: Initial outcome after selective intraarterial radionuclide therapy with yttrium-90 microspheres as salvage therapy for unresectable metastatic liver disease. Cancer Biother Radiopharm 28: 534-540, 2013.

128. Kucuk ON, Soydal C, Lacin S, Ozkan E and Bilgic S: Selective intraarterial radionuclide therapy with Yttrium-90 (Y-90) microspheres for unresectable primary and metastatic liver tumors. World J Surg Oncol 9: 86, 2011.

129. Björnsson B, Sparrelid E, Røsok B, Pomianowska E, Hasselgren K, Gasslander T, Bjørnbeth BA, Isaksson B and Sandström P: Associating liver partition and portal vein ligation for staged hepatectomy in patients with colorectal liver metastases - Intermediate oncological results. Eur J Surg Oncol 42: 531-537, 2016.

130. Kremer M, Manzini G, Hristov B, Polychronidis G, Mokry T, Sommer CM, Mehrabi A, Weitz J, Büchler MW and Schemmer P: Impact of neoadjuvant chemotherapy on hypertrophy of the future liver remnant after associating liver partition and portal vein ligation for staged hepatectomy. J Am Coll Surg 221: 717-728.e1, 2015.

131. Torres OJ, Fernandes ES, Oliveira CV, Lima CX, Waechter FL, Moraes-Junior JM, Linhares MM, Pinto RD, Herman P and Machado MA: Associating liver partition and portal vein ligation for staged hepatectomy (ALPPS): The Brazilian experience. Arq Bras Cir Dig 26: 40-43, 2013. 